\title{
Characterization of T cell immunity in chronic hepatitis B virus-infected mothers with postpartum alanine transaminase flare
}

\author{
Meiting Huang ${ }^{1,2+}$, Yunfei Gao ${ }^{3+}$, Xueru Yin ${ }^{1}$, Xuelian Zhang ${ }^{1}$, Yaohua Hao ${ }^{1}$, Jing Hu ${ }^{4}$ and Zhihua Liu ${ }^{1,5^{*}}$
}

\begin{abstract}
Background: Postpartum alanine transaminase (ALT) flares occur frequently in chronic hepatitis B virus (HBV)infected mothers with antepartum antiviral therapy (AVT). We aimed to characterize the T cell immunity in HBVinfected mothers experiencing postpartum ALT flares.
\end{abstract}

Methods: Twenty HBV-infected pregnant women who received AVT at 26-28 weeks of gestation were enrolled and followed up until 15-18 weeks postpartum. Among the 20 HBV-infected pregnant women, 6 experienced postpartum ALT flare (AF mothers), while 14 did not (NAF mothers). T lymphocyte phenotypes and functions were analyzed using flow cytometry.

Results: Compared to NAF mothers, the quantitative HBsAg levels in AF mothers decreased significantly at 6-8 or 15-18 weeks postpartum. Significant differences in HBeAg levels between these groups were only found at delivery. Regulatory T cell (Treg) numbers in AF mothers were lower than those of NAF mothers before AVT; however, there were no significant differences in Treg numbers at other follow-up points. Expression of other $T$ cell phenotypes were similar between the two groups. T cells in AF mothers produced more pro-inflammatory cytokines (IFN-, , IL-21, TNF-a, IL-2) or less anti-inflammatory cytokine (IL-10) than those in NAF mothers before, during, or after antiviral treatment. The ratio of IFN- $\gamma$ to IL-10 producing by $\mathrm{CD}^{+}{ }^{+} \mathrm{T}$ cells or $\mathrm{CD}^{+} \mathrm{T}$ cells was higher in AF mothers than that in NAF mothers during pregnancy or after delivery.

Conclusions: The characteristics of T cell immunity was distinct between mothers with postpartum ALT flare and those without ALT flare from pregnancy to postpartum, which indicated that T cell immunity might get involved in postpartum ALT flare.

Keywords: Hepatitis B virus, Postpartum, Alanine transaminase flare, T cell immunity

\section{Background}

Globally, hepatitis B virus (HBV) infection continues to be a major public health problem. The World Health Organization (WHO) estimated that in 2015, 257 million people were living with chronic HBV infection,

*Correspondence: zhihualiu@126.com

${ }^{\dagger}$ Meiting Huang and Yunfei Gao have contributed equally to this work.

${ }^{1}$ Department of Infectious Diseases, Nanfang Hospital, Southern Medical

University, Guangzhou 510515, China

Full list of author information is available at the end of the article and that HBV-related diseases resulted in 887,000 deaths annually worldwide [1]. In highly endemic countries, mother-to-child transmission (MTCT) is the main route of HBV transmission; approximately $40-50 \%$ of $\mathrm{HBsAg}^{+}$patients acquire infections via MTCT [2]. According to the latest WHO estimates, the proportion of children under 5 who are chronically infected with hepatitis B virus has decreased from $5 \%$ in the pre-vaccination period from the 1980 s to the early 2000 s to less than $1 \%$ in 2019 [1]. 
Reducing the incidence of MTCT is still a major challenge. Studies have shown that the levels of HBV DNA in HBV-infected mothers is an independent risk factor for MTCT [3-5]. It was reported that MTCT did not occur in mothers with a viral $\operatorname{load}<6 \log _{10}$ copies/ $\mathrm{mL}$ [6]. Studies have shown that along with the administration of the HBV vaccine and immunoglobulin, antepartum antiviral therapy (AVT) can further reduce the incidence of MTCT in pregnant women with high viral loads [7-9]. Previous studies mainly focused on the effectiveness and safety of AVT, as well as the probability and severity of maternal alanine transaminase (ALT) flare after delivery [10]. The characteristics of postpartum ALT flare are mainly mild to moderate abnormalities, which can resolve spontaneously in the majority of mothers [11]. Currently, whether antiviral intervention during pregnancy increases the incidence of postpartum ALT flare remains controversial [7, 12, 13].

A successful pregnancy depends on the immune system of a pregnant woman, which not only needs to tolerate paternal antigens, but also needs to protect the woman and growing fetus against invading pathogens [14]. During the various stages of pregnancy, the immune system of pregnant women is dynamically changed. Pro-inflammatory immunity is dominant in the first trimester of pregnancy, while the second phase of pregnancy is predominantly anti-inflammatory. Pro-inflammatory immunity becomes dominant again in the last stage of pregnancy [15]. Studies have shown that regulatory $\mathrm{T}$ cell (Treg) frequency in the peripheral blood of pregnant women is decreased during pregnancy, which may be caused by changes in estrogen and progesterone levels [16]. This decrease may also occur due to maternal Tregs migrating to the maternal-fetal surface to prevent maternal-fetal rejection, resulting in decreased peripheral blood Treg frequency [17]. Therefore, the immune status of chronic HBV-infected pregnant women is different from that of chronic HBV-infected women who are not pregnant. These alterations reverse rapidly after delivery. Current hypotheses infer that alterations in the immune system during pregnancy might be responsible for a high rate of postpartum ALT flares in HBV-infected women [18]. However, immunological characteristics of HBVinfected mothers experiencing postpartum ALT flare has not been investigated.

This study aimed to characterize the T cell immunity of HBV- infected mothers and explore the immunological mechanisms of postpartum ALT flare by comparing $\mathrm{T}$ cell immunity of HBV-infected mothers who experienced postpartum ALT flare with HBV-infected mothers without ALT flare.

\section{Patients and methods}

\section{Patients}

From September 2017 to April 2020, 20 pregnant women with chronic HBV infections who received prophylactic antiviral intervention (telbivudine or tenofovir) for the prevention of MTCT were enrolled and followed up at the Nanfang Hospital in Guangzhou, China. These pregnant women were in the phase of immune tolerance of chronic HBV infection at enrollment, showing $\mathrm{HBeAg}$ positivity, normal level of ALT, and high level of HBV DNA $\left(\geq 6 \log _{10} \mathrm{IU} / \mathrm{mL}\right.$ ) before antiviral intervention. All subjects recruited for this study were negative for hepatitis $\mathrm{C}$ virus and human immunodeficiency virus. Additionally, those receiving concurrent treatment involving cytotoxic drugs, immune modulators, glucocorticoids, as well as those with major systemic disease malignancies, liver cirrhosis, heart diseases, or renal dysfunctions were excluded.

Short-term AVT was administered to the subjects beginning at week $26-28$ of gestation until delivery. They were visited at week $26-28$ of gestation (before antiviral intervention), 1 month after antiviral intervention, at delivery, 6-8 weeks postpartum, and 15-18 weeks postpartum. ALT flare was defined as $\geq 2 \times$ upper limit of normal (ULN). ALT flare mothers (AF mothers) were $\mathrm{HBV}$-infected mothers experiencing a postpartum ALT flare $(n=6)$, while non-ALT flare mothers (NAF mothers) were $\mathrm{HBV}$-infected mothers with postpartum $\operatorname{ALT}<2 \times \operatorname{ULN}(\mathrm{n}=14)$.

\section{Virological and serological assessments}

The levels of serum HBsAg and $\mathrm{HBeAg}$ were measured using a Roche Elecsys assay (Roche, Basel, Switzerland). Serum HBV DNA levels were quantitatively determined by real-time polymerase chain reaction (PCR) using a commercial nucleic acid diagnostic kit (Sansure Biotech, Changsha, China) with an lower limit of detection (LOD) of $100 \mathrm{IU} / \mathrm{mL}$. Serological markers and HBV DNA assays were performed at the Laboratory of Viral Hepatitis Research, Nanfang Hospital (Guangzhou, China). The levels of serum ALT and aspartate transaminase (AST) were tested at the department of clinical laboratory of Nanfang Hospital (Guangzhou, China).

\section{Flow cytometric analysis of peripheral blood mononuclear cells (PBMCs)}

Peripheral blood venous samples were obtained from individual women before, during, and after stopping antiviral intervention. PBMCs were isolated by Ficoll-Hypaque density gradient centrifugation and cryopreserved in liquid nitrogen for deferred analysis [19]. For flow cytometry analysis, thawed PBMCs were stained with Live/ 
Dead Fixable dead cell stain (eBioscience, San Diego, CA, USA) for $10 \mathrm{~min}$ at room temperature. The cells were then stained for $30 \mathrm{~min}$ at $4{ }^{\circ} \mathrm{C}$ in the dark using the following antibodies (Abs): peridinin chlorophyll protein complex (PerCP)-Cy5.5- or fluorescein isothiocyanate (FITC)-antiCD4 (clones SK3 and RAP-T4, respectively; BD Biosciences, San Jose, CA, USA), FITC- or allophycocyanin (APC)-anti-CD8 (clone RPA-T8; BD Biosciences, San Jose, CA, USA), phycoerythrin (PE)-anti-CD45RA (HI100; BD Biosciences, San Jose, CA, USA), PE-CY7-anti-CD62L (clone DREG-56; BD Biosciences, San Jose, CA, USA), PE-CY7-anti-CD25 (clone M-A251; BD Biosciences, San Jose, CA, USA), APC-anti-CD69 (clone FN50; Biolegend, San Diego, CA, USA), PE-CY7-anti-CD38 (clone HIT2; BioLegend, San Diego, CA, USA) and PE-anti-PD-1 (clone MIH4; BD Biosciences, San Jose, CA, USA). Intranuclear APC-anti-forkhead box P3 (FOXP3; clone PCH101; eBioscience, San Diego, CA, USA) staining was performed according to the manufacturer's instructions. The stained cells were evaluated by flow cytometry using the BD FACSDiva system (BD Biosciences, San Jose, CA, USA), and the data were analyzed using FlowJo software (TreeStar Inc., Ashland, OR, USA) [20].

\section{Flow cytometric analysis of intracellular cytokine staining (ICS)}

For analyzing intracellular cytokine production, $5 \times 10^{5}$ cells/well were stimulated with $5 \mu \mathrm{g} / \mathrm{mL}$ of anti-CD3 monoclonal antibody (mAb; clone 145-2C11; BD Biosciences) and $5 \mu \mathrm{g} / \mathrm{mL}$ of soluble anti-CD28 $\mathrm{mAb}$ (clone 37.51; BD Biosciences, San Jose, CA, USA) in a 96-well flat-bottomed plate at $37^{\circ} \mathrm{C}$ for $24 \mathrm{~h}$. Brefeldin A $(10 \mu \mathrm{g} /$ $\mathrm{mL}$; BD Biosciences, San Jose, CA, USA) was added during the last $6 \mathrm{~h}$ of incubation. The cells were stained with Live/Dead Fixable dead cell stain (eBioscience, San Diego, CA, USA) at room temperature. After being washed, the cells were stained with PerCP-Cy5.5-antiCD4 and FITC-anti-CD8 at $4{ }^{\circ} \mathrm{C}$ for $30 \mathrm{~min}$. The surfacestained cells were fixed and permeabilized using a fixing/ permeabilizing reagent (BD Biosciences, San Jose, CA, USA) for $20 \mathrm{~min}$, followed by staining with PE-Cy7-antiinterferon (IFN)-y (clone B27; BD Biosciences, San Jose, CA, USA), PE-anti-interleukin (IL)-10 (clone JES3-9D7; Biolegend, San Diego, CA, USA), PE-anti-IL-21 (clone 3A3-N2.1; BD Biosciences, San Jose, CA, USA), APCanti-tumor necrosis factor (TNF)- $\alpha$ (clone 6401.1111; BD Biosciences, San Jose, CA, USA), PE-anti-IL-2 (clone MQ1-17H12; BD Biosciences, San Jose, CA, USA), and PE-Cy7-anti-IL-4 (clone 8D4-8; BD Biosciences San Jose, CA, USA) for $30 \mathrm{~min}$. Analyses were performed using the BD FACSDiva system (BD Biosciences, San Jose, CA, USA) and the FlowJo program (TreeStar Inc., Ashland, OR, USA) [21].

\section{Statistical analysis}

Data were expressed as either the median with a 95\% confidence interval (CI) or an interquartile range. The non-parametric Mann-Whitney $U$ test was used for statistical analysis based on two-tailed hypothesis tests using GraphPad Prism software (v.8.0; GraphPad Software, San Diego, CA, USA). P values $<0.05$ were considered significant.

\section{Results}

\section{Clinical characteristics of mothers with chronic HBV infection}

The clinical characteristics are comparable between the AF mothers and the NAF mothers. No statistically significant differences were found between the two groups in terms of age, number of births, weeks of gestation, AVT duration, or delivery methods. The levels of ALT or AST in HBV-infected mothers from the AF group or NAF group were all within the normal range before antiviral intervention, and the median levels of ALT (interquartile range) were $22.00(15.50,23.50)$ and $21.00(15.75$, 24.25) U/L, respectively, while the median levels of AST (interquartile range) were $21.00(16.50,29.00)$ and 19.00 $(16.75,21.25) \mathrm{U} / \mathrm{L}$, respectively, and no statistically significant differences were found. ALT and AST were within $1 \times$ ULN during antiviral treatment in the NAF mothers (including one month after antiviral intervention and at delivery), while one mother from the AF mothers had ALT over $2 \times$ ULN and her ALT levels returned to normal at delivery. Other AF mothers maintained ALT and AST levels in the normal range $(1 \times \mathrm{ULN})$ during antiviral intervention. At 6-8 weeks postpartum, 2 mothers (33.33\%) from the AF group developed transient ALT $>2 \times$ ULN. Another 4 mothers had ALT $>2 \times$ ULN at 15-18 weeks postpartum. Two mothers from the AF group continued to have ALT abnormalities, and antiviral therapy was restarted after delivery (Table 1).

\section{Virological and serological characteristics of HBV-infected mothers during pregnancy and postpartum}

The median levels of HBsAg in the AF mothers was lower than that of the NAF mothers before antiviral intervention, during AVT, or after antiviral treatment discontinuation postpartum. Significant differences were found only at $6-8$ weeks and $15-18$ weeks postpartum $(\mathrm{p}=0.459, \mathrm{p}=0.294, \mathrm{p}=0.415, \mathrm{p}=0.027$, $\mathrm{p}=0.021$ ). All mothers experienced a slight decline in the levels of HBsAg during AVT and increased levels after delivery (Fig. 1A). In addition, the levels of $\mathrm{HBeAg}$ in the AF group were lower than those in the NAF group at 5 follow-up points from 26 to 28 weeks of gestation to $15-18$ weeks after birth, with a statistically 
Table 1 Clinical characteristics of mothers with chronic HBV infection

\begin{tabular}{|c|c|c|c|}
\hline & AF mothers $(n=6)$ & NAF mothers $(n=14)$ & $P$ value \\
\hline Age (years) & $30.00(25.25,33.75)$ & $27.00(26.00,29.00)$ & 0.25 \\
\hline Gravidity & $1.00(1.00,1.50)$ & $1.00(1.00,2.00)$ & $>0.99$ \\
\hline Parity & $1.00(1.00,1.50)$ & $1.00(1.00,1.25)$ & $>0.99$ \\
\hline Delivery gestations (weeks) & $39.00(38.75,39.25)$ & $40.00(38.00,40.00)$ & 0.5 \\
\hline Duration of AVT (days) & $101.00(91.00,105.30)$ & $95.00(79.25,105.80)$ & 0.44 \\
\hline \multicolumn{4}{|l|}{ Type of delivery—no. (\%) } \\
\hline Vaginal & $5(83.33 \%)$ & $11(78.57 \%)$ & \multirow[t]{2}{*}{$>0.99$} \\
\hline Caesarean section & $1(16.67 \%)$ & $3(21.43 \%)$ & \\
\hline \multicolumn{4}{|c|}{ Before AVT (gestational 26-28 weeks) } \\
\hline $\mathrm{ALT}(\mathrm{U} / \mathrm{L})$ & $22.00(15.50,23.50)$ & $21.00(15.75,24.25)$ & 0.7 \\
\hline AST(U/L) & $21.00(16.50,29.00)$ & $19.00(16.75,21.25)$ & 0.54 \\
\hline \multicolumn{4}{|l|}{ Gestational 30-32 weeks } \\
\hline $\mathrm{ALT}(\mathrm{U} / \mathrm{L})$ & $27.50(16.00,47.00)$ & $16.00(12.75,25.25)$ & 0.15 \\
\hline AST(U/L) & $29.00(22.75,34.00)$ & $20.59(16.00,22.00)$ & 0.05 \\
\hline \multicolumn{4}{|l|}{ Delivery } \\
\hline $\mathrm{ALT}(\mathrm{U} / \mathrm{L})$ & $17.50(11.00,24.50)$ & $18.00(13.00,20.00)$ & 0.94 \\
\hline AST(U/L) & $22.00(15.25,25.25)$ & $21.00(16.25,25.75)$ & 0.98 \\
\hline \multicolumn{4}{|l|}{ Postpartum 6-8 weeks } \\
\hline $\mathrm{ALT}(\mathrm{U} / \mathrm{L})$ & $38.00(30.25,98.50)$ & $38.00(18.75,47.75)$ & 0.41 \\
\hline $\operatorname{ALT}(n,>2 \times U L N)$ & $2(33.33 \%)$ & 0 & 0.08 \\
\hline AST(U/L) & $29.50(19.00,86.50)$ & $25.50(19.00,36.00)$ & 0.51 \\
\hline $\operatorname{AST}(n,>2 \times \cup L N)$ & $2(33.33 \%)$ & 0 & 0.08 \\
\hline \multicolumn{4}{|l|}{ Postpartum 15-18 weeks } \\
\hline $\mathrm{ALT}(\mathrm{U} / \mathrm{L})$ & $106.60(40.00,215.80)$ & $28.00(23.50,46.00)$ & 0.03 \\
\hline $\operatorname{ALT}(n,>2 \times U L N)$ & $4(66.67 \%)$ & 0 & 0 \\
\hline AST(U/L) & $57.00(33.75,158.50)$ & $24.00(21.00,30.00)$ & 0 \\
\hline $\operatorname{AST}(n,>2 \times \cup L N)$ & $2(33.33 \%)$ & 0 & 0.08 \\
\hline
\end{tabular}

Data are shown as median (IQR interquartile range)

$A V T$ antepartum antiviral therapy; $A L T$ alanine transaminase; $A S T$ aspartate aminotransferase

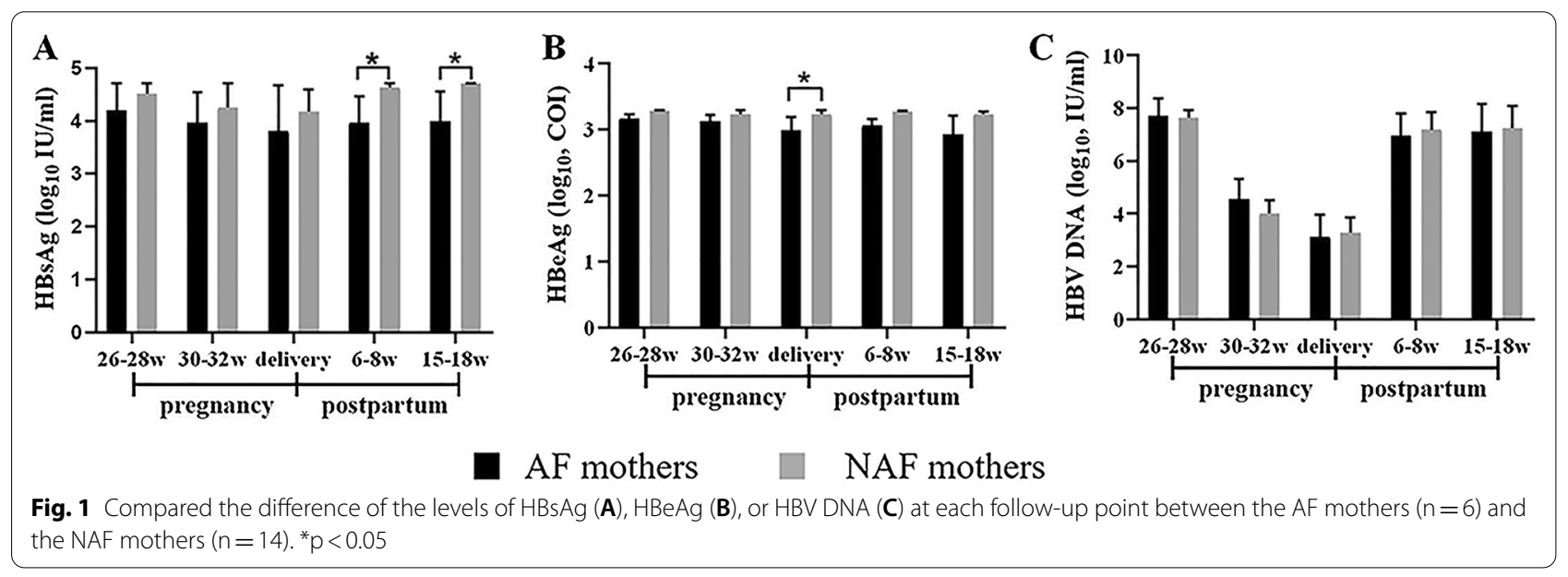


significant difference between the two groups only occurring at delivery $(\mathrm{p}=0.035)$ (Fig. 1B). With respect to HBV DNA levels, no significant difference was found between the AF and NAF mothers at any of the followup points (Fig. 1C).

\section{Comparison of the $\mathrm{CD}^{+} \mathrm{T}$ cell phenotypes of $\mathrm{AF}$ and NAF mothers before, during, and after AVT}

To analyze the characteristics of $\mathrm{CD} 4^{+} \mathrm{T}$ cell phenotypes in AF mothers, we compared the differences in phenotype expression of $\mathrm{CD} 4^{+} \mathrm{T}$ cells based on the presence of CD45RA, CD62L, CD38, CD69, and PD-1 between the AF and NAF groups before, during, and after antiviral intervention (Fig. 2A-E). No significant differences were observed in the expression of CD45RA, CD62L, CD38, or PD-1 by CD $4^{+} \mathrm{T}$ cells at any of the follow-up points. However, we found that the activation marker CD69 was expressed by $\mathrm{CD} 4^{+}$ $\mathrm{T}$ cells in AF mothers at a significantly higher rate than that in NAF mothers at 26-28 weeks of gestation (before antiviral intervention) and 15-18 weeks after birth $(\mathrm{p}=0.04, \mathrm{p}=0.04)$ (Fig. 2D). We further examined the amount of Tregs $\left(\mathrm{CD} 4{ }^{+} \mathrm{CD} 25^{+}\right.$Foxp $\left.3^{+}\right)$ between the two groups before, during, and after antiviral intervention and found that the number of Tregs in AF mothers was significantly higher than that in NAF mothers before antiviral intervention (i.e. at $26-28$ weeks gestation) $(\mathrm{p}=0.02)$. There were no significant differences in the amounts of Tregs between the two groups during and after stopping antiviral intervention (Fig. 2F).

\section{Comparison of $\mathrm{CDB}^{+} \mathrm{T}$ cell phenotypes of $\mathrm{AF}$ and the NAF mothers before, during, and after AVT}

Representative FACS plots showing the phenotypes of $\mathrm{CD}^{+} \mathrm{T}$ cells based on the presence of CD45RA, CD62L, CD38, CD69, and PD-1 are shown in Fig. 3A. From 26 to 28 weeks gestation to $15-18$ weeks after birth, the numbers of $\mathrm{CD} 8^{+} \mathrm{CD} 45 \mathrm{RA}^{+}$cells, $\mathrm{CD} 8{ }^{+} \mathrm{CD} 62 \mathrm{~L}^{+}$cells, $\mathrm{CD} 8^{+} \mathrm{CD} 38^{+}$cells, $\mathrm{CD} 8^{+} \mathrm{CD} 69^{+}$ cells, and $\mathrm{CD} 8^{+} \mathrm{PD}-1^{+}$cells were similar between the $\mathrm{AF}$ and NAF mothers (Fig. 3B-F).

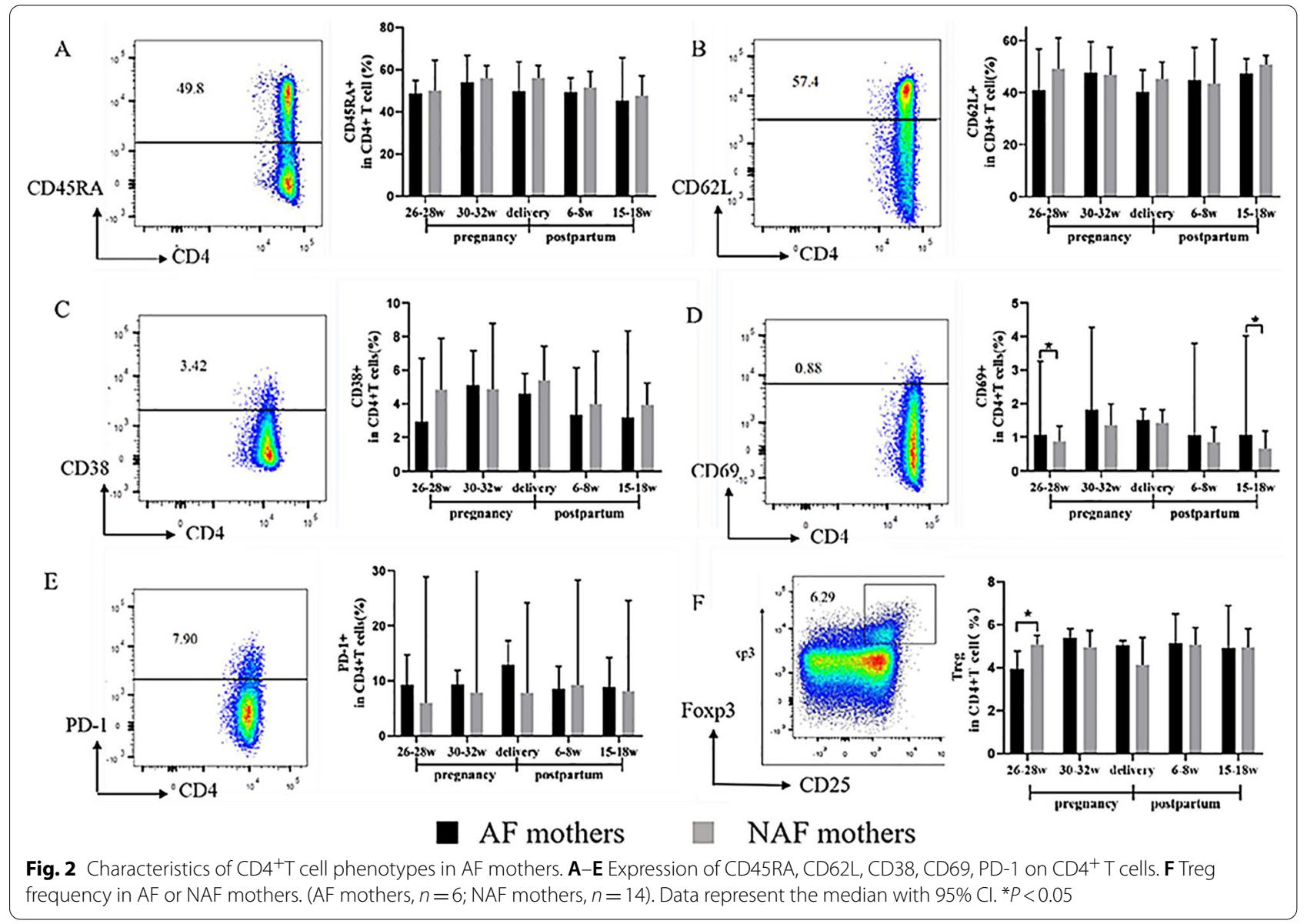



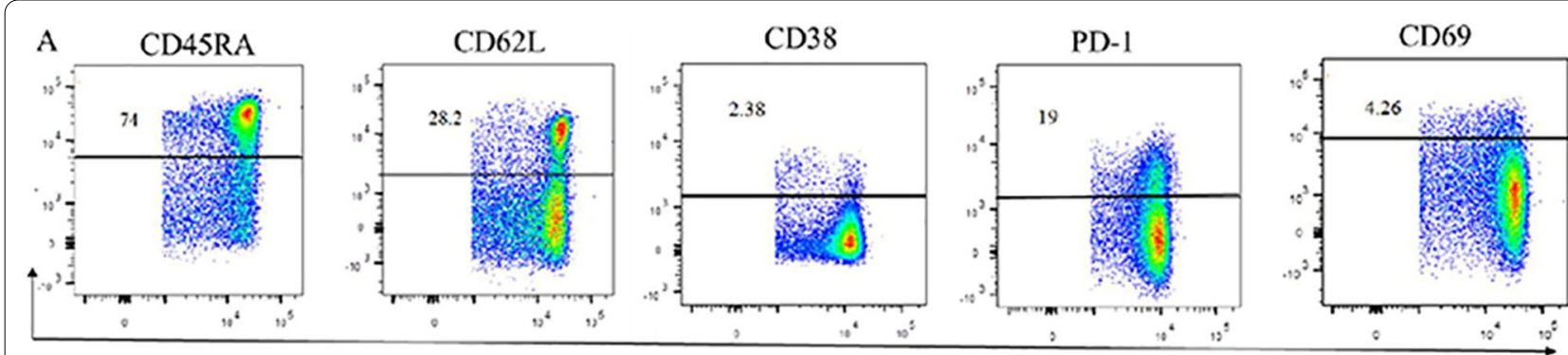

CD8

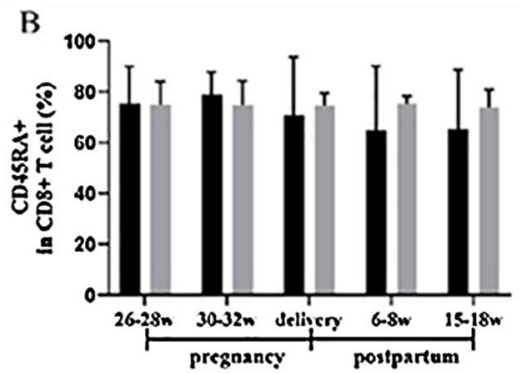

C

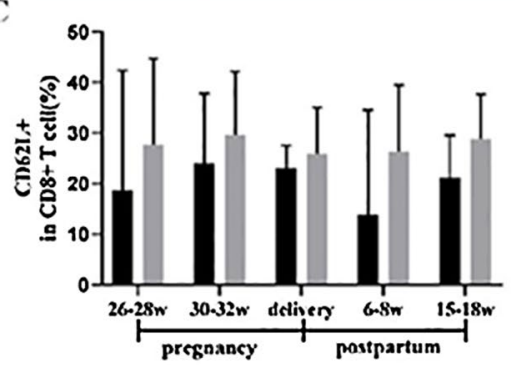

F
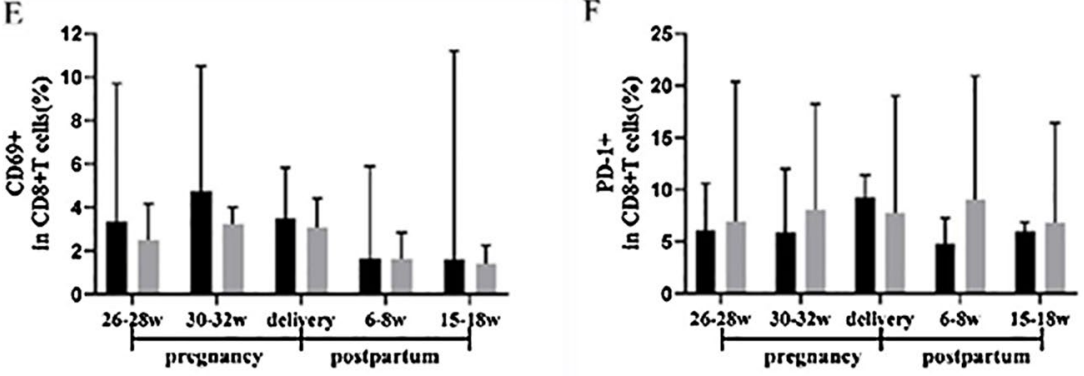

D

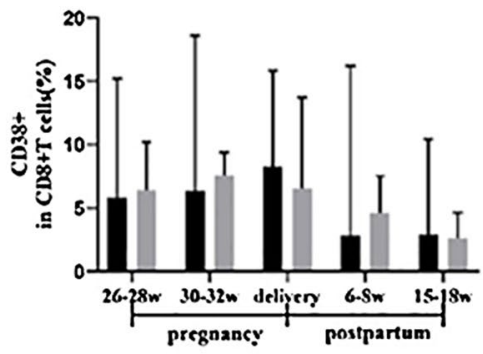

\section{AF mothers}

\section{NAF mothers}

Fig. 3 Characteristics of $C D 8^{+} T$ cell phenotypes in AF mothers. A Representative FACS plots showing the phenotype expression of CD4 ${ }^{+} \mathrm{T}$ cells based on the presence of CD45RA, CD62L, CD38, CD69, and PD-1. B-F Expression of CD45RA, CD62L, CD38, CD69, and PD-1 by CD8 ${ }^{+} \mathrm{T}$ cells. (AF mothers, $n=6$; NAF mothers, $n=14$ ). Data represent the median with $95 \% \mathrm{Cl}$. ${ }^{*} P<0.05$

\section{$\mathrm{CD}^{+}{ }^{\mathrm{T}}$ cells in AF mothers produced more pro-inflammatory cytokines}

Following anti-CD3/anti-CD28 stimulation, we analyzed the levels of cytokines secreted by $\mathrm{CD} 4^{+} \mathrm{T}$ cells in $6 \mathrm{AF}$ and 14 NAF mothers using flow cytometry. Representative FACS dot plots of cytokine production from $\mathrm{CD}^{+} \mathrm{T}$ cells are shown in Fig. 4A. Before antiviral treatment (at 26-28 weeks of gestation, Fig. 4B), $\mathrm{CD}^{+} \mathrm{T}$ cells in AF mothers secreted more IFN- $\gamma$, IL-21, and IL-2 than CD $4^{+} \mathrm{T}$ cells in NAF mothers $(\mathrm{p}=0.007, \mathrm{p}=0.035, \mathrm{p}=0.021)$. Additionally, it appears that the secretion of TNF- $\alpha$ by $C D 4^{+} \mathrm{T}$ cells was higher in AF mothers than that in NAF mothers $(p=0.087)$. However, compared to the $\mathrm{CD}^{+}{ }^{+} \mathrm{T}$ cells from NAF mothers, the cells from AF mothers displayed a reduced ability to secrete anti-inflammatory cytokine
IL-10 $(p=0.024)$. The secretion of IL-4 by CD4 ${ }^{+} \mathrm{T}$ cells was not significantly different between the two groups ( $p>0.999$ ) (Fig. 4B). During AVT (including one month after antiviral therapy and at delivery), there was no statistically significant difference in the secretion of various cytokines by $\mathrm{CD}^{+}{ }^{+} \mathrm{T}$ cells between the AF and NAF mothers (Fig. 4C, D). After stopping antiviral intervention (including at 6-8 weeks postpartum and 15-18 weeks postpartum), the ability of CD4 ${ }^{+} \mathrm{T}$ cells to secrete IFN- $\gamma$ was greater in AF mothers than that in NAF mothers $(p=0.049, p=0.035)$. Moreover, AF mothers displayed attenuated IL-10 secretion at $15-18$ weeks postpartum $(\mathrm{p}=0.004)$ (Fig. 4E, F). Finally, when comparing the frequency ratio of IFN- $\gamma$ secreting $\mathrm{CD}^{+} \mathrm{T}$ cells to IL-10-secreting $\mathrm{CD} 4^{+} \mathrm{T}$ cells in AF mothers to that of NAF mothers at all follow-up 

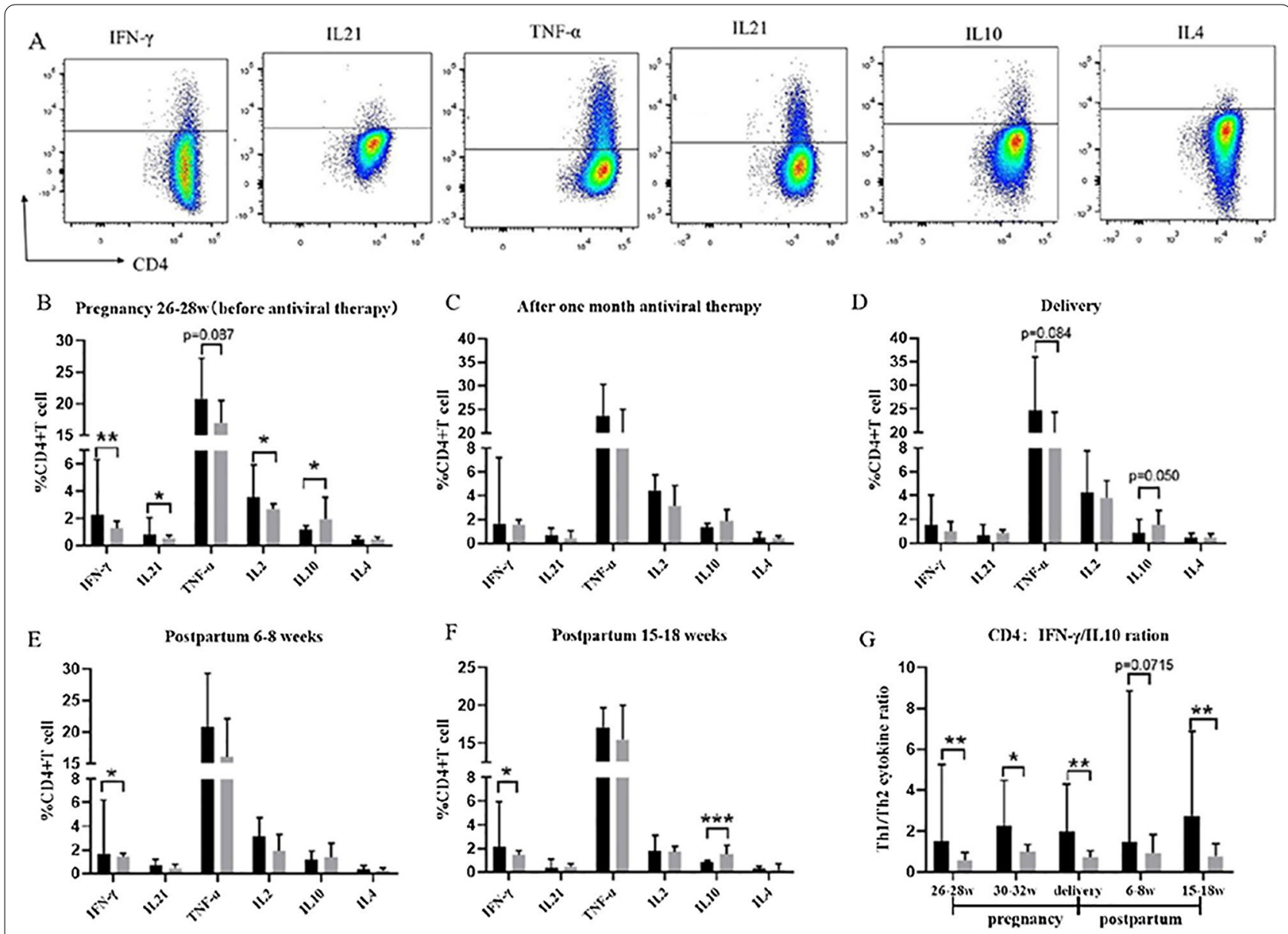

\section{$\mathrm{AF}$ mothers}

NAF mothers

Fig. $4 \mathrm{CD}^{+} \mathrm{T}$ cells in AF mothers tend to secrete pro-inflammatory cytokines. A Representative dot plots of the production of cytokines (IFN- $-{ }_{\text {, }}$ IL-21, TNF-a, IL-2, IL-10 and IL-4) in CD4 ${ }^{+}$T cells. B-F Percentages of cytokine-producing CD4 ${ }^{+}$T cells in AF $(n=6)$ or NAF mothers $(n=14)$ at 26-28 weeks of gestation, 30-32 weeks of gestation, delivery, 6-8 weeks postpartum, or 15-18 weeks postpartum. G Data representing the ratio of pro-inflammatory cytokine to anti-inflammatory cytokine (IFN-ү:IL-10) in CD4+ T cells from 26 to 28 weeks of gestation to 15-18 weeks postpartum. The data represent the median with $95 \% \mathrm{Cl}$. ${ }^{*}<<0.05$, ${ }^{*} P<0.005$

points, we found that the ratio in AF mothers was significantly higher than that in NAF mothers $(\mathrm{p}=0.002$, $\mathrm{p}=0.046, \mathrm{p}=0.001, \mathrm{p}=0.005)$ before antiviral intervention, one month after antiviral intervention, at delivery, and at 15-18 weeks postpartum. At 6-8 weeks postpartum, there was no significant difference in the ratio of pro-inflammatory/anti-inflammatory cytokines produced by $\mathrm{CD} 4^{+} \mathrm{T}$ cells, but a similar trend was observed ( $\mathrm{p}=0.072$ ) (Fig. 4G).

\section{$\mathrm{CD}^{+} \mathrm{T}$ cells from $\mathrm{AF}$ mothers produce more pro-inflammatory cytokines}

Representative FACS dot plots of pro-inflammatory cytokines (IFN- $\gamma$, IL-21, TNF- $\alpha$, and IL-2) and antiinflammatory cytokines (IL-4 and IL-10) produced by
$\mathrm{CD}^{+} \mathrm{T}$ cells are shown in Fig. 5A. When comparing the pro-inflammatory and anti-inflammatory cytokine secretion from $\mathrm{CD} 8^{+} \mathrm{T}$ cells in the AF mothers with that of the NAF mothers before, during, and after AVT, we found that the amount of IFN- $\gamma$-secreting $\mathrm{CD}^{+} \mathrm{T}$ cells in AF mothers was significantly higher than that of NAF mothers at 26-28 weeks of gestation and at 6-8 weeks postpartum $(\mathrm{p}=0.046, \mathrm{p}=0.035)$. The amount of IL-10-secreting $\mathrm{CD}^{+} \mathrm{T}$ cells in the NAF group was significantly higher than that in the AF group at all follow-up points $(\mathrm{p}=0.005, \mathrm{p}=0.044, \mathrm{p}=0.039, \mathrm{p}=0.025$, $\mathrm{p}=0.002$ ) (Fig. $5 \mathrm{~B}-\mathrm{F}$ ). In addition, after analyzing the ratio of IFN- $\gamma$-secreting $\mathrm{CD}^{+} \mathrm{T}$ cells to IL-10-secreting $\mathrm{CD}^{+} \mathrm{T}$ cells at each follow-up point, the $\mathrm{AF}$ mothers were found to have a significantly higher ratio of 

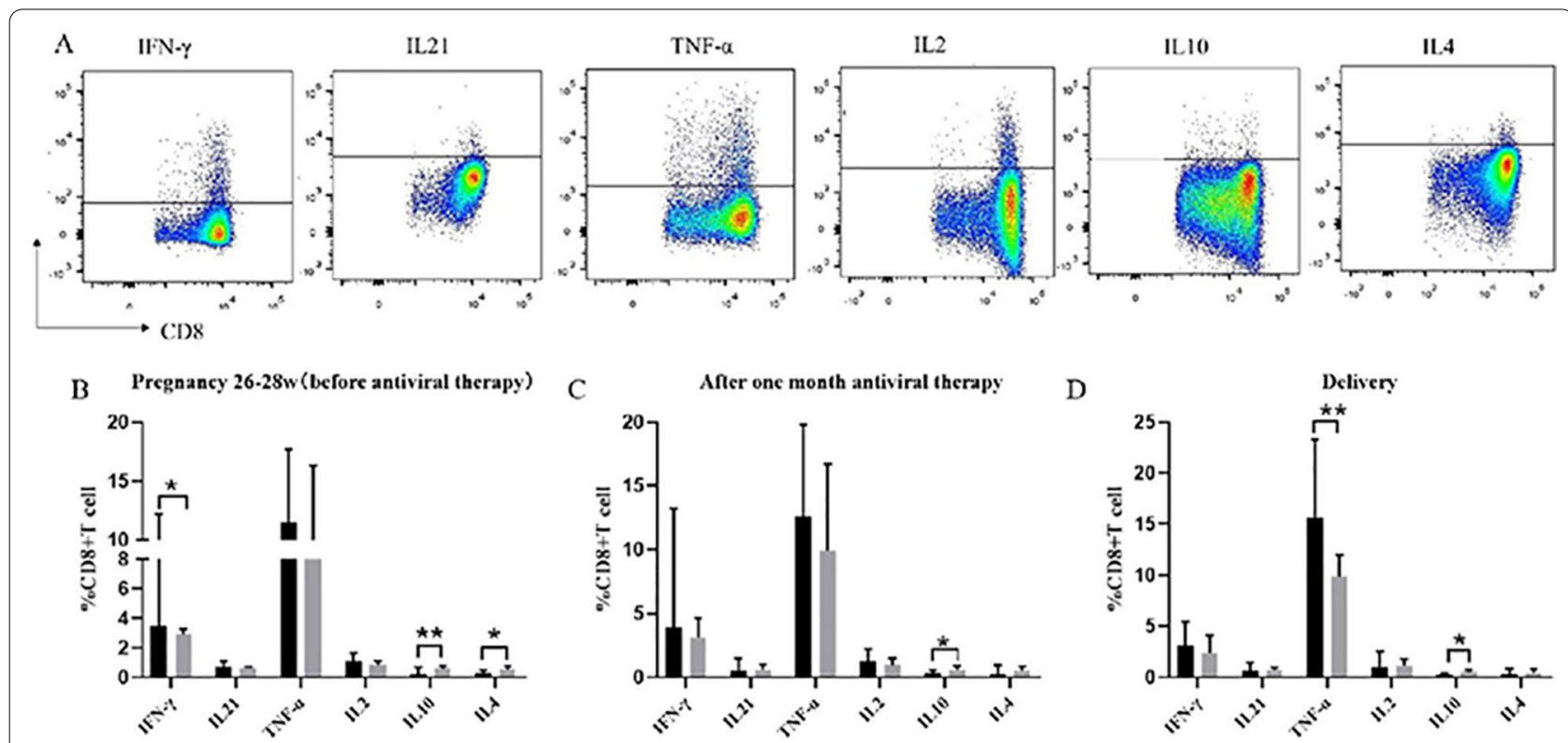

$$
\text { C }
$$

After one month antiviral therapy

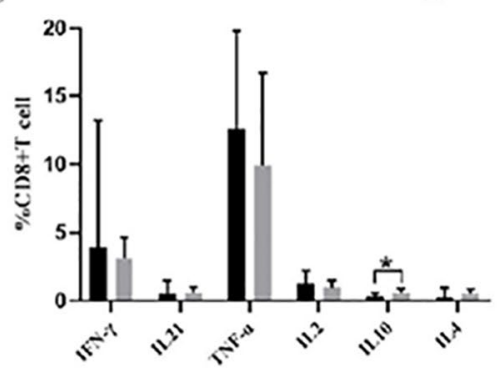

D

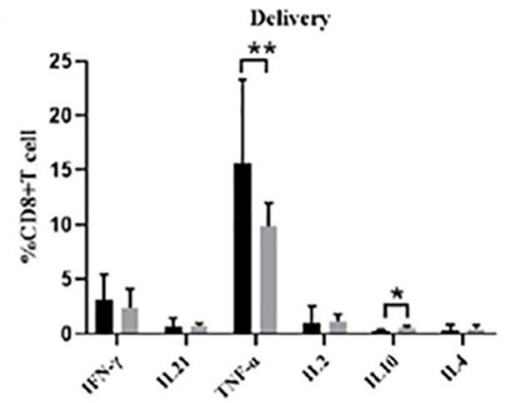

$\mathrm{E}$

Postpartum 6.8 wocks

F

Postpartum 15-18 weeks

G
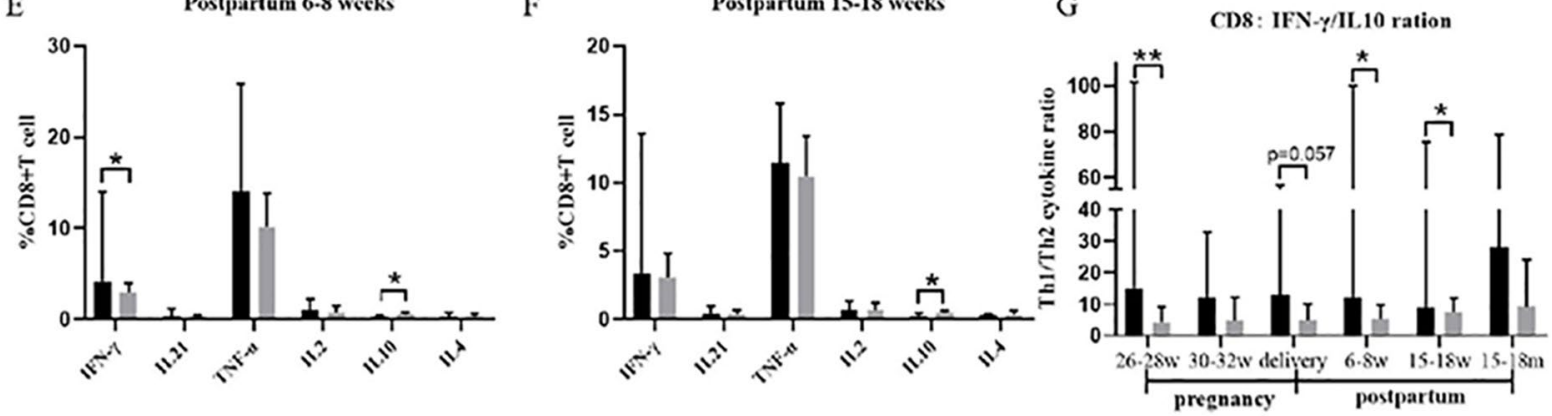

AF mothers

NAF mothers

Fig. $5 \mathrm{CD}^{+} \mathrm{T}$ cells in AF mothers tend to secrete pro-inflammatory cytokines. A Representative dot plots of the production of cytokines (IFNIL-21, TNF-a, IL-2, IL-10, and IL-4) in CD8 ${ }^{+}$T cells. B-F Percentages of cytokine-producing CD8 ${ }^{+}$T cells in AF mothers $(n=6)$ or NAF mothers $(n=14)$ at 26-28 weeks of gestation, 30-32 weeks of gestation, delivery, 6-8 weeks postpartum, or 15-18 weeks postpartum. G The data represent the ratio of pro-inflammatory cytokine to anti-inflammatory cytokine (IFN- $-\mathrm{I}: \mathrm{L}-10)$ in CD8 ${ }^{+}$T cells from 26 to 28 weeks of gestation to $15-18$ weeks postpartum. The data represent the median with $95 \% \mathrm{Cl} .{ }^{*} P<0.05,{ }^{* *} P<0.005$

these cells than that of the NAF mothers before and after stopping AVT (6-8 weeks postpartum and 15-18 weeks postpartum $)(p=0.007, p=0.046, p=0.027)$. The median ratio of the AF mothers was higher than that of the NAF mothers at 30-32 weeks of gestation or at delivery, but no significant difference was observed $(\mathrm{p}=0.127$, $\mathrm{p}=0.058$ ) (Fig. 5G). Briefly, the ability of $\mathrm{CD}^{+} \mathrm{T}$ cells to secrete pro-inflammatory factors in the AF group was higher than that in the NAF group, while the ability to secrete the anti-inflammatory factor IL-10 was significantly weaker than that in the NAF group.

\section{Discussion}

In recent years, hepatitis B guidelines recommended that antiviral intervention should be administered to pregnant women with high HBV DNA levels to block MTCT and be withdrew after delivery [22-24]. It was reported that some of the HBV-infected mothers who underwent antiviral interventions in late pregnancy experienced postpartum ALT flares after drug withdrawal [25-28]. A large sample size, retrospective study showed that elevated ALT levels and detectable levels of HBV DNA at delivery were independent risk factors for postpartum disease flares [27]. However, there are limited data on $\mathrm{T}$ cell immunity in HBV-infected patients with postpartum ALT abnormalities. Thus, in the present study, we sought to examine $\mathrm{T}$ cell immunity of $\mathrm{HBV}$-infected mothers 
who experienced postpartum ALT flare, with the aim of exploring immune mechanism which might underlie the postpartum ALT flares.

Our study found that 95\% (19/20) of HBV-infected pregnant women maintained ALT normalization during the antiviral period. Postpartum ALT flares appeared in $30 \%(6 / 20)$ of $\mathrm{HBsAg}^{+} / \mathrm{HBeAg}^{+}$mothers after stopping antiviral intervention, among which 4 cases spontaneously returned to normal and the other 2 cases required restarting antiviral treatment. We found that HBsAg levels in the AF mothers were significantly lower than those in the NAF mothers at 6-8 weeks and 15-18 weeks postpartum. This result showed that chronic HBV-infected mothers with lower HBsAg levels are prone to have ALT flare after delivery.

It has been reported that postpartum liver damage may occur due to changes in maternal immune status $[11,18]$. In this study, we found that before antiviral treatment (at 26-28 weeks of gestation), compared to the Treg amounts in NAF mothers, those in AF mothers decreased, and $\mathrm{T}$ cells in AF mothers secreted significantly higher amounts of pro-inflammatory cytokines (IFN- $\gamma$, IL-21, IL-2) and less amounts of anti-inflammatory cytokines (IL-10). The ratio of pro-inflammatory cytokine (IFN- $\gamma$ ) to anti-inflammatory cytokine (IL-10) in $\mathrm{CD}_{4}^{+}$or $\mathrm{CD}^{+} \mathrm{T}$ cells was higher in $\mathrm{AF}$ mothers than that in NAF mothers before, during, or after AVT. Tregs are currently recognized as a $\mathrm{CD} 4^{+} \mathrm{T}$ cells that display significant immunosuppressive effects. The maintenance of immune tolerance is mainly manifested by Tregs having an immunosuppressive effect on HBV-specific $\mathrm{T}$ cell responses, leading to chronic infection $[29,30]$. In addition, pro-inflammatory cytokines (such as IFN- $\gamma$ and IL-12) prevent immune tolerance and eradicate virus, while anti-inflammatory cytokines (IL-10) maintain immune tolerance [31, 32].

Compared to NAF mothers, AF mothers had lower Treg frequency at 26-28 weeks of gestation, stronger pro-inflammatory immunity and weaker anti-inflammatory immunity from 26 to 28 weeks of gestation to 15-18 weeks postpartum. These results indicated that HBV-infected mothers had distinct characteristics of $\mathrm{T}$ cell immunity, which played an important role in postpartum ALT flares. Those mothers with lower Treg frequency and higher ratio of pro-inflammatory cytokine to anti-inflammatory cytokine in $\mathrm{CD} 4^{+}$or $\mathrm{CD} 8^{+} \mathrm{T}$ cells will be more likely to experience ALT flare postpartum. From above, we infer that when pro-inflammatory immunity is dominant (i.e., $\mathrm{T}$ cells secrete more pro-inflammatory cytokines and less anti-inflammatory cytokines; Treg amounts are decreased) in HBV-infected pregnant women, the patients' immune tolerance tends to be attenuated, so that postpartum ALT flares are more likely to occur.

Because the differences in the profile of pro-inflammatory/anti-inflammatory cytokines existed as early as 26-28 weeks of gestation (before AVT), and remained to be significant until postpartum 15-18 weeks, we considered that distinct characteristics of $\mathrm{T}$ cell immunity was caused by neither AVT nor status of pregnancy. At baseline, the HBV-infected mothers exhibited distinct characteristics of $\mathrm{T}$ cell immunity, although their biochemical parameters were normal. Therefore, it is necessary to monitor ALT levels postpartum in chronic HBV-infected pregnant women and more attention should be paid to those with ALT flare because they are likely to experience the transition from immune tolerance phase to immune clearance phase.

This study was limited by the lack of a long-term follow-up analysis of $\mathrm{HBsAg}^{+} / \mathrm{HBeAg}^{+}$mothers with high viral load who did not undergo AVT; consequently, we could not analyze whether AVT affected the incidence and severity of postpartum ALT flares. In addition, the sample size of this study was small, especially in AF group. More studies with larger sample size are needed to further validate the results of this study.

\section{Conclusion}

In this study, we found that the characteristics of $\mathrm{T}$ cell immunity was distinct between AF and NAF mothers from pregnancy to postpartum. $\mathrm{T}$ cell immunity in AF mothers was characterized by lower Treg frequency and higher ratio of pro-inflammatory cytokine to anti-inflammatory cytokine in CD4+ or CD8+ T cells. The results indicated that maternal immune status might play an important role in postpartum ALT flare in HBV-infected mothers. Therefore, the HBV-infected mothers with ALT flare postpartum should be monitored closely because they might experience the transition from immune tolerance phase to immune active phase.

\footnotetext{
Abbreviations

ALT: Alanine transaminase; HBV: Hepatitis B virus; AVT: Antepartum antiviral therapy; AF: ALT flare; NAF: Non-ALT flare; Treg: Regulatory T cell; WHO: The World Health Organization; MTCT: Mother-to-child transmission; ULN: The upper limit of normal; AST: Aspartate transaminase; PBMCs: Peripheral blood mononuclear cells; PerCP: Peridinin chlorophyll protein; FITC: Fluorescein isothiocyanate; APC: Allophycocyanin; PE: Phycoerythrin; FOXP3: Forkhead
} 
box P3; ICS: Intracellular cytokine staining; mAb: Monoclonal antibody; IFN: Interferon; IL: Interleukin; TNF: Tumor necrosis factor; Cl: Confidence interval.

\section{Acknowledgements}

We are grateful to the mothers enrolled in this study, and we thank our colleagues in the Department of Infectious Diseases, Nanfang Hospital, for their help in collecting samples and clinical data.

\section{Authors' contributions}

ZHL, YFG, JH and MTH designed the study. MTH collected samples, performed the experiments, conducted the statistical analyses, and drafted the manuscript. XRY, XLZ and YHH collected clinical data and followed up the patients. $\mathrm{ZHL}, \mathrm{YFG}, J \mathrm{H}$ and MTH revised the manuscript. All authors read and approved the final manuscript.

\section{Funding}

This work was supported by the National Natural Science Foundation of China (Grant No.81673243), the Chinese National Research Grant of the Thirteenth Five-Year Plan for the Key Projects in Infectious Diseases (2017ZX10201201), and Sanming Project of Medicine in Shenzhen (SZSM201911001).

\section{Availability of data and materials}

The datasets used during the current study are available from the corresponding author upon reasonable request.

\section{Declarations}

\section{Ethics approval and consent to participate}

This study was conducted in accordance with Good Clinical Practice, following local regulations and ethical principles described in the Declaration of Helsinki. The study protocol was approved by the Institutional Review Board of Nanfang Hospital, Southern Medical University (IRB No. NFEC-2019-197), and written informed consent was obtained from all subjects.

\section{Consent for publication}

Not applicable.

\section{Competing interests}

The authors declare that they have no competing interests.

\section{Author details}

${ }^{1}$ Department of Infectious Diseases, Nanfang Hospital, Southern Medical University, Guangzhou 510515, China. ${ }^{2}$ Present Address: Department of Infectious Diseases, Huizhou Third People's Hospital, Guangzhou Medical University, Huizhou 516002, China. ${ }^{3}$ Present Address: Department of Obstetrics and Gynaecology, Zengcheng Branch of Nanfang Hospital, Southern Medical University, Guangzhou 511340, China. ${ }^{4}$ Department of Nosocomial Infection Administration, Zhujiang Hospital, Southern Medical University, Guangzhou 510280, China. ${ }^{5}$ Liver Diseases Center, Shenzhen Hospital of Southern Medical University, Shenzhen 518000, China.

Received: 9 March 2021 Accepted: 25 August 2021

Published online: 06 September 2021

\section{References}

1. World Health Organization. Fact sheet on hepatitis B. https://www.who.int/ news-room/fact-sheets/detail/hepatitis-b. Accessed 27 July 2020

2. Su W, Chen S, Yang C, Chuang P, Chang H, Chang M. The impact of universal infant hepatitis $B$ immunization on reducing the hepatitis $B$ carrier rate in pregnant women. J Infect Dis. 2019;220(7):1118-26.

3. Peng T, Cai Q, Yang M, Chen S, Chen F, Wang M, Peng L, Wong G, Shen C, Cheng W, et al. Epidemiological trends and virological traits of hepatitis B virus infection in pregnant women and neonates. Arch Virol. 2019;164(5):1335-41.

4. Terrault NA, Levy MT, Cheung KW, Jourdain G. Viral hepatitis and pregnancy. Nat Rev Gastroenterol Hepatol. 2021;18(2):117-30.

5. Yi W, Pan CQ, Hao J, Hu Y, Liu M, Li L, Liang D. Risk of vertical transmission of hepatitis B after amniocentesis in HBs antigen-positive mothers. J Hepatol. 2013:60(3):523-9.
6. Zou H, Chen Y, Duan Z, Zhang H, Pan C. Virologic factors associated with failure to passive-active immunoprophylaxis in infants born to HBsAg-positive mothers. JViral Hepat. 2012;19(2):e18-25.

7. Pan CQ, Duan Z, Dai E, Zhang S, Han G, Wang Y, Zhang H, Zou H, Zhu B, Zhao W, et al. Tenofovir to prevent hepatitis $B$ transmission in mothers with high viral load. N Engl J Med. 2016;374(24):2324-34.

8. Brown RJ, McMahon BJ, Lok AS, Wong JB, Ahmed AT, Mouchli MA, Wang Z, Prokop $\sqcup$, Murad MH, Mohammed K. Antiviral therapy in chronic hepatitis B viral infection during pregnancy: a systematic review and meta-analysis. Hepatology. 2016;63(1):319-33.

9. Funk AL, Lu Y, Yoshida K, Zhao T, Boucheron P, van Holten J, Chou R, Bulterys M, Shimakawa Y. Efficacy and safety of antiviral prophylaxis during pregnancy to prevent mother-to-child transmission of hepatitis B virus: a systematic review and meta-analysis. Lancet Infect Dis. 2021;21(1):70-84.

10. Li Z, Duan X, Hu Y, Zhou M, Liu M, Kang K, Cai H, Yi W, Fu D, Gao X. Efficacy and safety of lamivudine or telbivudine in preventing mother-to-child transmission of hepatitis B virus: a real-world study. Biomed Res Int. 2020;2020:1374276.

11. Bzowej NH, Tran TT, Li R, Belle SH, Smith Cl, Khalili M, Chung R, Tsai N, Terrault N. Total alanine aminotransferase (ALT) flares in pregnant North American women with chronic hepatitis B infection: results from a prospective observational study. Am J Gastroenterol. 2019;114(8):1283-91.

12. Zhang H, Pan CQ, Pang Q, Tian R, Yan M, Liu X. Telbivudine or lamivudine use in late pregnancy safely reduces perinatal transmission of hepatitis B virus in real-life practice. Hepatology. 2014;60(2):468-76.

13. Jourdain G, Ngo-Giang-Huong N, Harrison L, Decker L, Khamduang W, Tierney C, Salvadori N, Cressey TR, Sirirungsi W, Achalapong J, et al. Tenofovir versus placebo to prevent perinatal transmission of hepatitis B. N Engl J Med. 2018;378(10):911-23.

14. Zhang $\mathrm{YH}$, Sun HX. Immune checkpoint molecules in pregnancy: focus on regulatory T cells. Eur J Immunol. 2020;50(2):160-9.

15. Chatterjee P, Chiasson VL, Bounds KR, Mitchell BM. Regulation of the antiinflammatory cytokines interleukin-4 and interleukin-10 during pregnancy. Front Immunol. 2014;5:253.

16. Mjosberg J, Svensson J, Johansson E, Hellstrom L, Casas R, Jenmalm MC, Boij $R$, Matthiesen $L$, Jonsson Jl, Berg $G$, et al. Systemic reduction of functionally suppressive CD4 ${ }^{\text {dim }}$ CD $25^{\text {high }}$ Foxp $3^{+}$Tregs in human second trimester pregnancy is induced by progesterone and 17 beta-estradiol. J Immunol. 2009:183(1):759-69.

17. Tilburgs T, Roelen DL, van der Mast BJ, de Groot-Swings GM, Kleijburg C, Scherjon SA, Claas FH. Evidence for a selective migration of fetus-specific $\mathrm{CD}^{+} \mathrm{CD} 25$ bright regulatory $T$ cells from the peripheral blood to the decidua in human pregnancy. J Immunol. 2008:180(8):5737-45.

18. Joshi SS, Coffin CS. Hepatitis B and pregnancy: virologic and immunologic characteristics. Hepatol Commun. 2019:4(2):157-71.

19. Bøyum A. Isolation of lymphocytes, granulocytes and macrophages. Scand J Immunol. 1976;5(s5):9-15.

20. Barathan M, Mohamed R, Vadivelu J, Chang LY, Vignesh R, Krishnan J, Sigamani P, Saeidi A, Ram MR, VeluV, et al. CD8 ${ }^{+} T$ cells of chronic HCV-infected patients express multiple negative immune checkpoints following stimulation with HCV peptides. Cell Immunol. 2017;313:1-9.

21. Huang M, Gao Y, Liao D, Li J, Tang B, Ma Y, Yin X, Li Y, Liu Z. Effects of intrauterine exposure to maternal-derived HBeAg on T cell immunity in cord blood. Scand J Immunol. 2020;92(2):e12914.

22. European Association for the Study of the Liver. EASL 2017 Clinical Practice Guidelines on the management of hepatitis B virus infection. J Hepatol. 2017;67(2):370-98

23. Chinese Society of Hepatology, Chinese Medical Association; Chinese Society of Infectious Diseases, Chinese Medical Association. The guidelines of prevention and treatment for chronic hepatitis B (2019 version). Zhonghua Gan Zang Bing Za Zhi. 2019;27(12):938-61.

24. Hou J, Cui F, Ding Y, Dou X, Duan Z, Han G, Jia J, Mao Q, Li J, Li Z, et al. Management algorithm for interrupting mother-to-child transmission of hepatitis $B$ virus. Clin Gastroenterol Hepatol. 2019;17(10):1929-36.

25. Giles M, Visvanathan K, Lewin S, Bowden S, Locarnini S, Spelman T, Sasadeusz J. Clinical and virological predictors of hepatic flares in pregnant women with chronic hepatitis B. Gut. 2015:64(11):1810-5.

26. Chang CY, Aziz N, Poongkunran M, Javaid A, Trinh HN, Lau D, Nguyen MH. Serum alanine aminotransferase and hepatitis B DNA flares in pregnant and postpartum women with chronic hepatitis B. Am J Gastroenterol. 2016:111(10):1410-5. 
27. YiW, Pan CQ, Li M, Wan G, Lv Y, Liu M, Hu Y, Zhang Z, Xie Y. The characteristics and predictors of postpartum hepatitis flares in women with chronic hepatitis B. Am J Gastroenterol. 2018;113(5):686-93.

28. Kushner T, Shaw PA, Kalra A, Magaldi L, Monpara P, Bedi G, Krok K, Centkowski S, Dalldorf K, D'Souza J, et al. Incidence, determinants and outcomes of pregnancy-associated hepatitis B flares: a regional hospital-based cohort study. Liver Int. 2018;38(5):813-20.

29. Liu C, Xu L, Xia C, Long Y, Liu C, Lu S, Song Y. Increased proportion of functional subpopulations in circulating regulatory T cells in patients with chronic hepatitis B. Hepatol Res. 2020;50(4):439-52.
30. Stoop JN, van der Molen RG, Baan CC, van der Laan LW, Kuipers EJ, Kusters $J G$, Janssen HLA. Regulatory T cells contribute to the impaired immune response in patients with chronic hepatitis B virus infection. Hepatology 2005;41(4):771-8.

31. Ye B, Liu X, Li X, Kong H, Tian L, Chen Y.T-cell exhaustion in chronic hepatitis B infection: current knowledge and clinical significance. Cell Death Dis. 2015;6(3):e1694.

32. Gu Y, Lian Y, Gu L, Chen L, Li X, Zhou L, Huang Y, Wang J, Huang Y. Correlations between cytokines produced by T cells and clinical-virological charact

Publisher's Note

Springer Nature remains neutral with regard to jurisdictional claims in published maps and institutional affiliations.
Ready to submit your research? Choose BMC and benefit from:

- fast, convenient online submission

- thorough peer review by experienced researchers in your field

- rapid publication on acceptance

- support for research data, including large and complex data types

- gold Open Access which fosters wider collaboration and increased citations

- maximum visibility for your research: over $100 \mathrm{M}$ website views per year

At BMC, research is always in progress.

Learn more biomedcentral.com/submissions 